\title{
Design of a switch-mode power supply with soft switching and analog control
}

\author{
E.Baghaz, A. Naamane, N.K M'sirdi \\ Aix Marseille Univ, Université de Toulon, CNRS, LIS, Marseille, France \\ Avenue escadrille Normandie Niemen 13397 Marseille cedex 20 \\ Email : aziz.naamane@1sis-lab.fr
}

\begin{abstract}
In high-power applications to meet high-efficiency and green standards. Some power-supply designers have found it easier to use a D/DC, full-bridge converter. This is because this kind of converter can obtain zero-voltage switching on the primary side of the converter reducing switching losses, and EMI and increasing overall efficiency.

The purpose of this paper is the design of a switch mode power supply for industrial applications (vehicle battery charger, power supply for a helicopter...,).

This Full Bridge DC/DC converter controlled by an analog control. This shows several advantages as simple implementation, compactness with satisfactory performance. The simulation results obtained are compared with a Full Bridge Converter controlled by UCC 28950 which is a digital Texas Instruments component. The designed power supply operates with an efficiency of more than $90 \%$.
\end{abstract}

Keywords: Full Bridge DC/DC converter, analog control, UCC28950 controller, power supply, output

\section{Introduction}

In the field of power electronics, the choice of DC/DC converters depends the load specification of the desired application. Such as conventional DC/DC converters (Boost, Buck,...) are easy to implement, they require only one PWM signal to control the power switch. While, this type of converters are intended for limited current and voltage applications. Second, they suffer from a low-yield problem [14] because of the use of hard-switching controls, resulting in very significant output power loss during the switching of the transistor [1-4]. To address this problem, there are several structures of alternative power DC/DC converters for power applications $[5,12]$. In this context a new high power full bridge DC/DC converter is studied, with its analog controller. This proposed structure allows soft switching of the used transistors and as a result the overall efficiency is improved. The simulation results obtained are compared with those of converter controlled by a digital controller designed and produced by Texas Instruments.

\section{Structure and operation of a Full Bridge DC/DC converter controlled by an analog circuit}

Figure 1 represents the synoptic diagram of the Full Bridge DC/DC converter, Figure 2, represents a full bridge phase $\mathrm{DC} / \mathrm{DC}$ converter with its analog controller TA, TB, TC, and TD transistors form the complete bridge on the primary side of the $\mathrm{T} 2$ transformer, they switch with an appropriate cyclic ratio . TE, and TF represent the transistors on the secondary side of the $\mathrm{T} 2$ transformer. While $\mathrm{L}_{\text {Out }}$ and $\mathrm{V}_{\text {Out }}$ form the output filter. The Tr inductance is designed to assist the T2 transformer leakage inductance when operating in resonance with the internal capacity of the MOSFET and facilitates zero voltage switching (ZVT). 


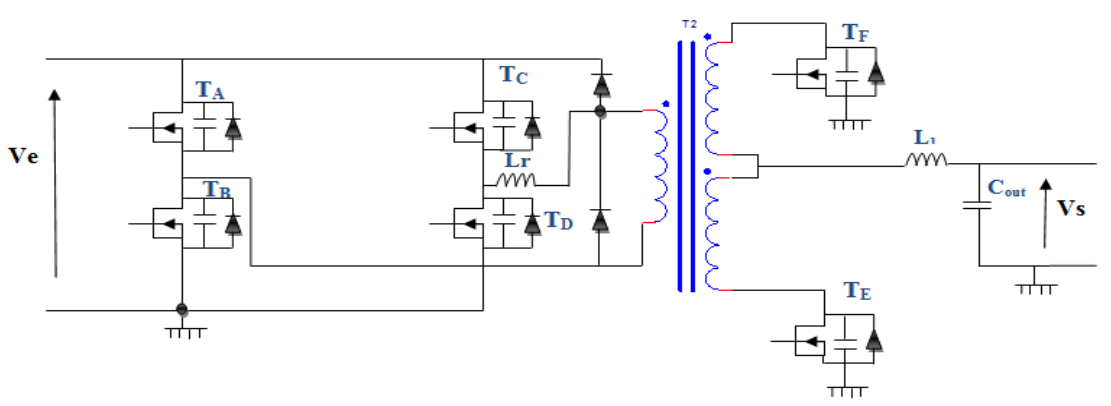

Figure1 Full bridge DC/DC

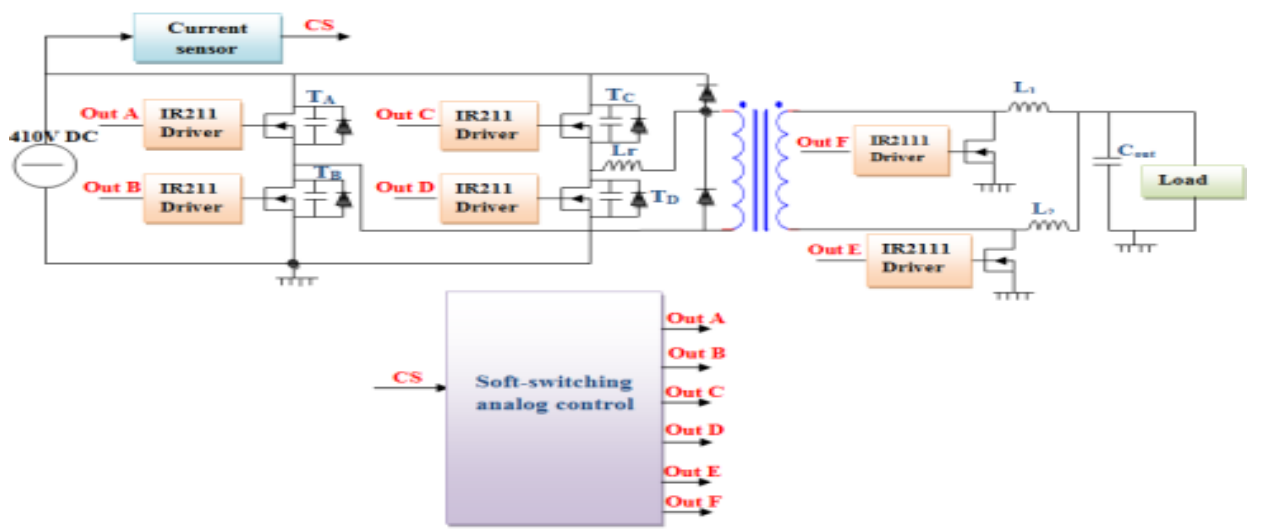

Figure 2. Control scheme of DC/DC converter

The analog control, it is based on the acquisition of the current generated by the input generator and the output voltage in order to generate 6 PWM synchronized signals to ensure the switching of the 4 Transistors (TA, TB, TC, TD) on the primary side of the transformer and those on the secondary side (TE, TF). As it is shown in the next figure A PI corrector is used

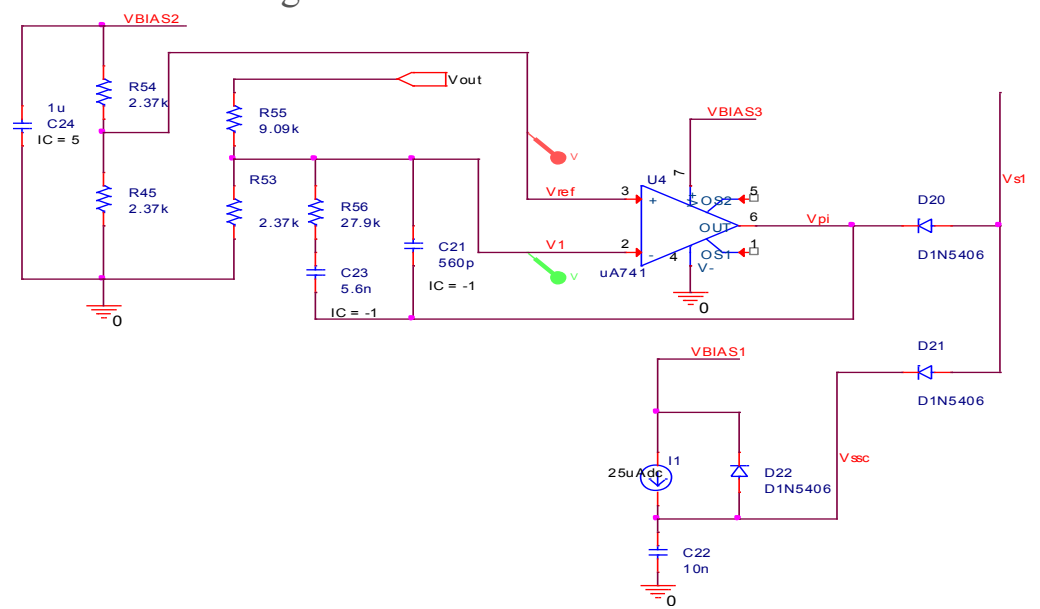

Figure 3 PI Corrector

The Acquisition of the current was carried out on the basis of the circuit shown in Figure 4, the transformer used for this application has a transformation ratio (m) of 100.

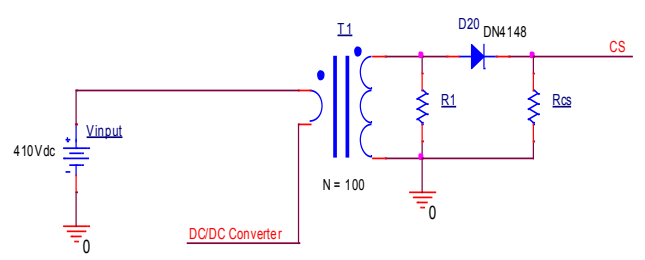

Figure 4 : current acquisition 


$$
\begin{gathered}
I_{p 1}=\left(\frac{P S}{V S * \eta}+\frac{\Delta I_{L 1}}{2}\right) * \frac{1}{m}+\frac{V_{I N M I N} * D_{M A X}}{L_{M A G} * 2 * F_{S W}}=6.88 A \quad, R_{C S}=\frac{\left(V_{p}-0.3\right)}{\left(\frac{\left.I_{p 1} * 1.1\right)}{n}=20.89 \Omega\right.} \\
R_{7}=n * R_{C S}=800 \Omega
\end{gathered}
$$

The PWM signal is obtained by the following circuit :

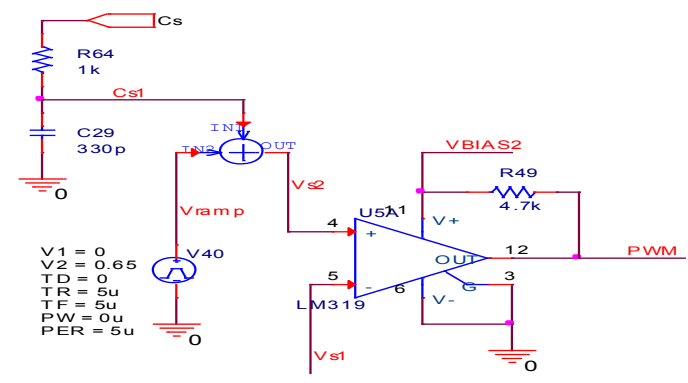

The PWM signal obtained above is connected with a flip flop JK toggle. The Q output of this toggle will only change the state if the PWM signal connected to its CLK input is in the rising front. The signal $\mathrm{Q}$ and $\mathrm{Q}^{-}$at the output of the JK are two PWM signals (QC and QD) that will control a leg of the DC/DC converter Full Bridge. Then, a delay of 360ns is applied to the front amount of two signals $\mathrm{Q}^{\text {and }} \mathrm{Q}^{-}$, which ensures a switching to zero voltage (soft switching), avoiding the switching losses. The simulation results are shown in Figure 6, by connecting the PWM signal obtained to a JK flip flop, we obtain the signal from Figure 7 in green. One notices the JK has a rising edge behavior, for its state changes. The outputs Q and Q', at the output of the JK flip flop, are shifted at each front up to 60ns. (Fig 6 F \& G).

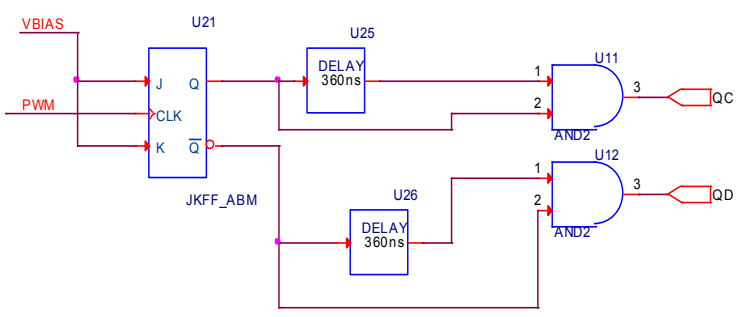

Fig.5. PWM signals connected to transistors $T_{C}$ et $T_{D}$.
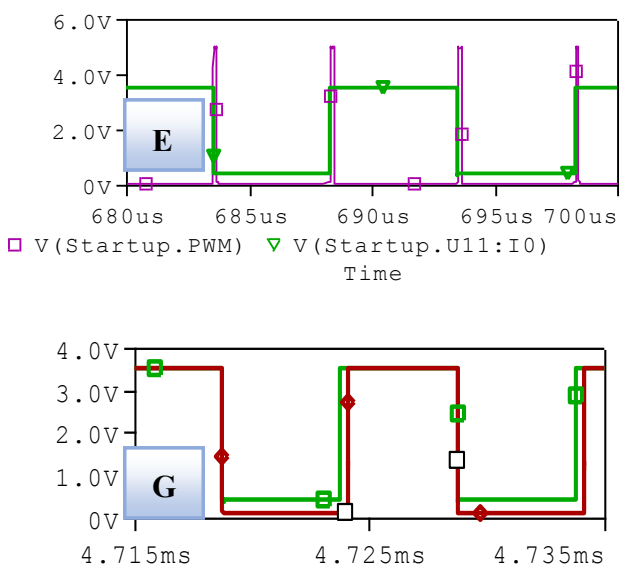

$\square \mathrm{V}($ Startup.U21:Qbar) $\diamond \mathrm{V}($ Startup:QD) Time

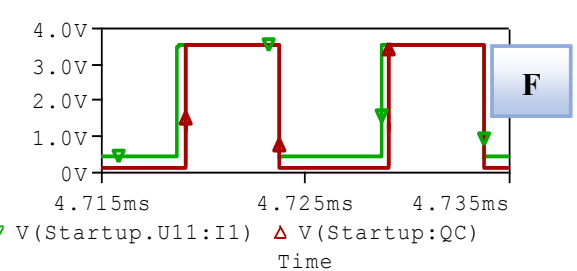

Fig. 6. Signals generated by the circuit in Figure 5: E: PWM signal connected to the flip flop JK input (pink) and the one at its output (green); F: PWM signal QC (in red) of the JK flip flop (in green); G: QD PWM signal (in red). the output (Q) of the JK flip flop (in green).

Fig 6, represents the complete circuit of the switching mode power supply, implanted in the Pspice simulator. We represent in the following the different simulation results obtained. 


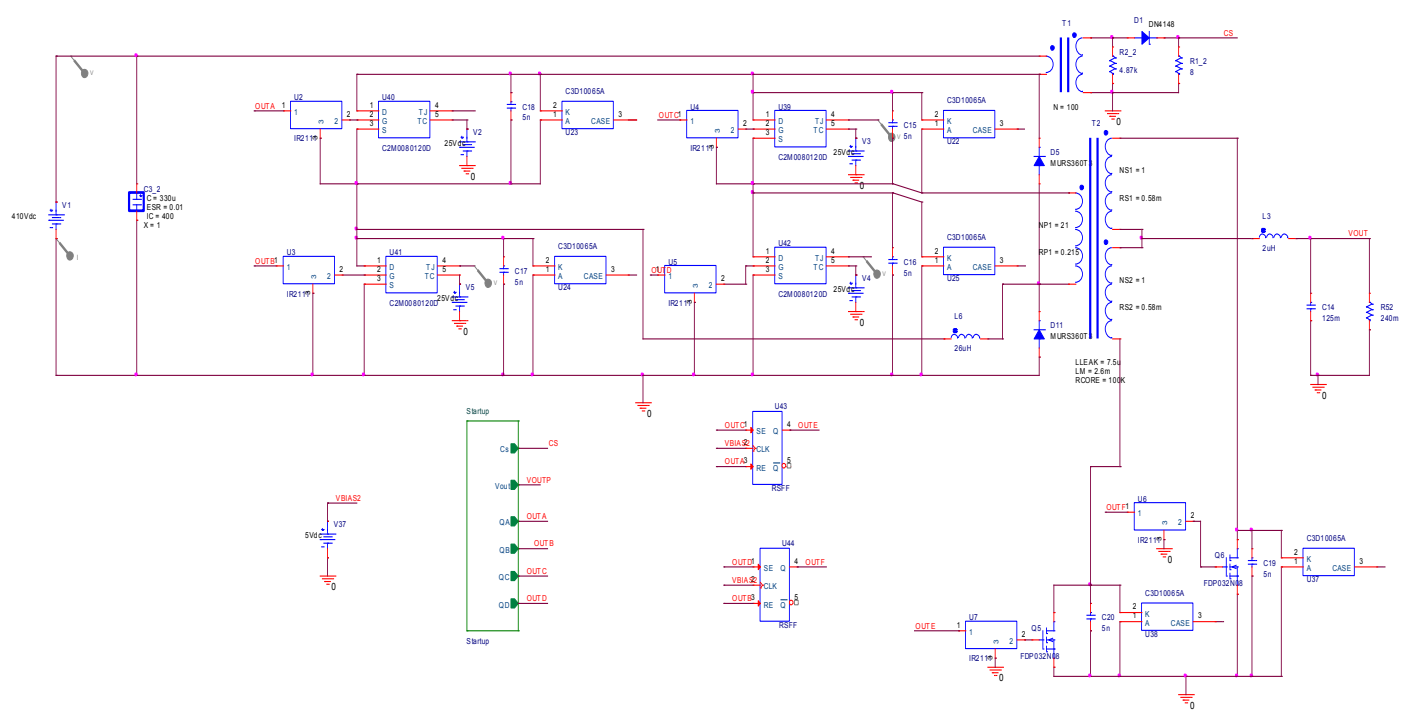

Fig.6. Complete circuit of the Supply switch mode

\section{Performance comparis on of the designed control and the UCC28950 controller}

In order to show the performance of the analog control designed during this work, we compared the different signals of the Full Bridge converter, controlled by the designed control and the UCC28950 controller. The different results obtained are shown in Figure 7.It is to note that the results of the system controlled by the analog control designed are shown in Figure 7 on the left and those of system controlled by UCC28950 [11] are shown on the Same figure on the right. Based on the results obtained,

The comparison of the OUTA PWM signal generated by the two controls shows that they have the same cyclic ratio of 0.47 , the same frequency of $100 \mathrm{kHz}$.
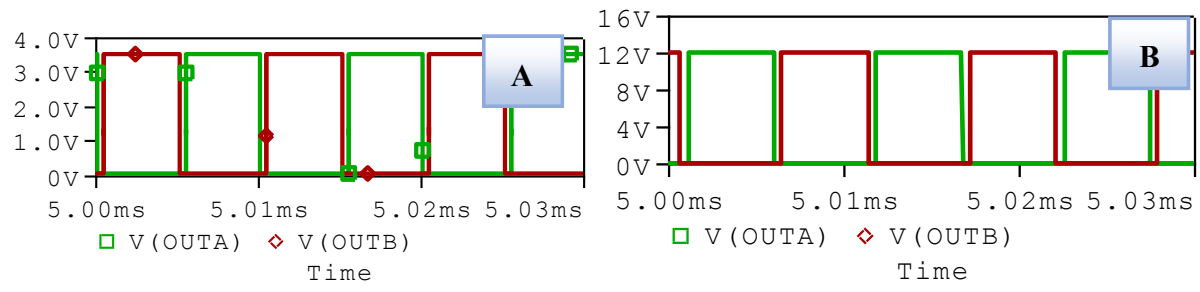

Fig.7. OUT A PWM signals,
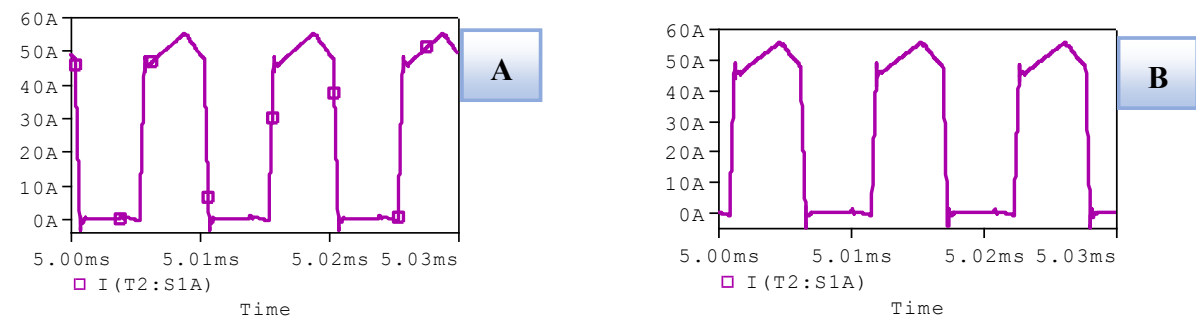

Fig.8. Output transformer current generated

The electrical quantities at the output (voltage, current) generated by the analog control designed (Figure 9 A) are identical with those generated by the UCC28950 (Figure 9 B). The analog control designed in this work has a satisfactory performance, efficiency is higher than $90 \%$ (figure 9C). It is identical to that generated by the UCC28950 controller (figure 9D).

So, the analog control designed during this work generates well-synchronized PWM signals, which ensures smooth transistors switching of the DC/DC converter. In order to clearly show these advantages, 
we have shown in Figure 9 and F, the power losses and the junction temperature of the four transistors, of the Full Bridge DC/DC converter, during the transistor switching. It appears that, the power losses in each transistor is low, they do not exceed $0.5 \mathrm{~W}$. Then the junction temperature of each transistor is about $50{ }^{\circ} \mathrm{C}$. The results obtained clearly show the advantage of the control designed during this work.
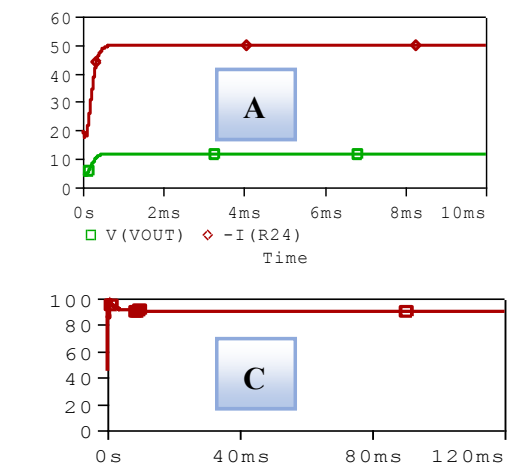

ㅁ $((-\mathrm{I}(\mathrm{R} 24) * \mathrm{~V}(\mathrm{VOUT})) /(\mathrm{AVG}(\mathrm{I}(\mathrm{T} 1: \mathrm{P} 1 \mathrm{~A}$

) ) $* V(T 1: P(A))) * 100$

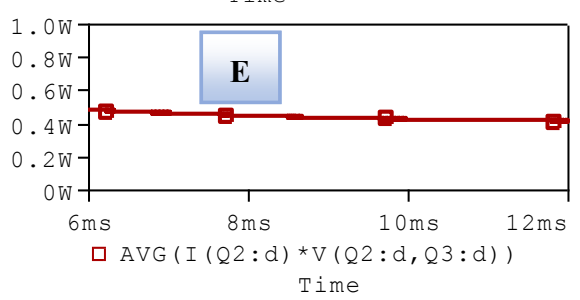

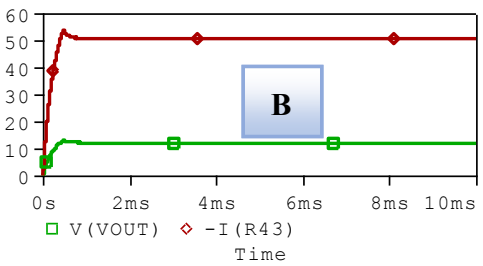

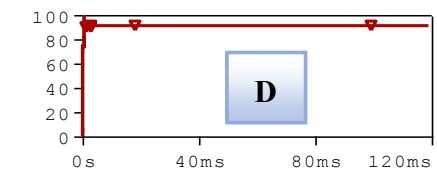

$\nabla((\mathrm{V}(\mathrm{VOUT}) *-\mathrm{I}(\mathrm{R} 43)) /(\mathrm{AVG}(\mathrm{I}(\mathrm{T} 1: \mathrm{P} 1 \mathrm{~A}$ )) $* \operatorname{V(VIN:+))}) * 100$

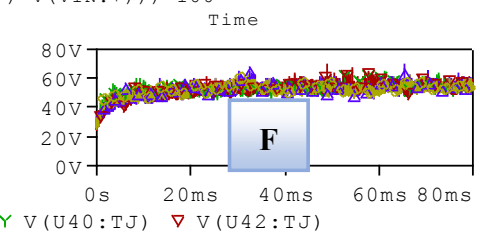

$Y \mathrm{~V}(\mathrm{U} 40: \mathrm{TU}) \quad \nabla V(\mathrm{U} 42: \mathrm{TJ})$

$\Delta V(U 39: T J) \& V(U 41: T J)$

Time

Fig. 9. Electrical quantities at the output of the DC/DC converter generated by the two controls:

A (B): Voltage and current generated by analog control (UCC28950)

C (D): Overall output of the inverter controlled by the analog control (UCC28950)

$\mathrm{E}$ and F: dissipated loss in the TA transistor, of the DC/DC converter controlled by the analog control, and its junction temperature.

\section{Conclusion}

In this paper, we have developed a power supply with a high current. It allows to generate a voltage of $12 \mathrm{~V}$ current, a current of $50 \mathrm{~A}$, a power of $600 \mathrm{~W}$. It operates at a switching frequency of $100 \mathrm{kHz}$. This power supply is represented by a Full Bridge DC/DC converter controlled by an analog Control. Pspice provides an effective environment for modeling and simulation of this proposed DC/DC converters. The simulation results show the reasonability and validity of the control design. As conclusion analog controller model gives very good dynamic respond compare with commercial digital controller model. It achieves our goal; it gives the same results as the commercial controller. Other advantages include smaller size and lighter weight (from the elimination of low frequency transformers which have a high weight) and lower heat generation due to higher efficiency.

\section{References}

1. E. Baghaz, M. Melhaoui, M.F. Yaden and K. Kassmi. Photovoltaic System Equipped with a DC/DC Buck Converter and a MPPT Command Ensuring an Optimal Functioning

2. http://vincent.boitier.free.fr/TER/809PET-boost-converter-efficiency-calculations.pdf

3. Elhadi BAGHAZ. Architectures discrétisées de gestion de l'énergie fournie par les systèmes photovoltaïques. Thèse soutenue à l'université Mohamed Premier d'Oujda, Juin 2015.

4. Cedric Cabal. Optimisation énergétique de l'étage d'adaptation électronique dédié à la conversion photovoltaïque. Thèse Délivrée par l'Université Toulouse III - Paul Sabatier, décembre 2008.

5. L. Balogh, "The current-doubler rectifier: An alternative rectification technique for push-pull and bridge converters," Unitrode Integrated Circuit Corporation, Design note, DN-63, 2001, pp.1-5.

6. L. Balogh, "Design Review :100 W, $400 \mathrm{KHz}$ DC-DC converter with current doubler synchronous rectification achieves 92\% efficiency". Texas Intrument, Design Review, 2001, pp.1-40. 
7. Z. Sun, B. Eng, "Full bridge DC/DC converter with zero current switching synchronous rectification for auxiliary power units,"McMaster University, 2014.

8. X. Zhao, J.M. Guerrero, and X. Wu,'Review of aircraft electric power systems and architectures,' in Proc. IEEE International Energy Conference (Energy Con'14), 2014.

9. N. Kutkut, "A full bridge soft switched telecom power supply with a current doubler rectifier," in Proc. Telecommunications Energy Conference, 1997. INTELEC 97., 19th International, Melbourne, Vic., 19-23 Oct 1997, pp.344-351

10. M. O'Loughlin, "UCC28950 600-W, phase-shifted, full-bridge application report," TI Lit. No. SLUA560B, pp. 1-30, Sept. 2010.

11. http://www.ti.com/lit/ds/symlink/ucc28950.pdf

12. http://www.wolfspeed.com/media/downloads/161/C2M0025120D.pdf 